\title{
Trimetazidine in Stable angina pectoris and Type 2 Diabetes Mellitus: Safety \& Effectiveness: A Descriptive study
}

\author{
Authors \\ Dr Rajiv Girdhar ${ }^{1}$, Dr Ram Chaitanya Kothapalli ${ }^{2}$, Dr Nareshchand Hegde $\mathbf{H}^{3}$, \\ Dr Aashish D Rayapati ${ }^{4}$ \\ ${ }^{1}$ Assistant Professor in DM Cardiology \\ ${ }^{2}$ Post Graduate in General Medicine \\ ${ }^{3}$ Associate Professor in CTVS Dept \\ ${ }^{4}$ Intern in Rajarajeswari Medical College \& Hospital
}

\begin{abstract}
Aim \& Methods
An observational, non interventional, open-label clinical study assessed the effectiveness/safety of trimetazidine in 101 patients with stable angina pectoris and Type 2 diabetes mellitus.

Results: Trimetazidine-based therapy was effective in stable coronary artery disease, with significant improvements from baseline ( $p<0.05)$ in: number of angina attacks/week $(2.9 \pm 2.4$ vs $1.1 \pm 1.6)$, angina severity (Canadian Cardiovascular Society Classification $1.9 \pm 0.8$ vs $1.2 \pm 0.8$ ), exercise capacity (metabolic equivalents $6.8 \pm 1.7 \mathrm{vs} 6.5 \pm 1.7$ ), and exercise-induced myocardial ischemia (min $5.5 \pm 2.5 \mathrm{vs}$ $6.5 \pm 2.6)$.
\end{abstract}

Discussion: Trimetazidine treatment significantly $(p<0.05)$ improved glucose metabolism, lowered HbAlc $(7.1 \pm 1.1 \%$ vs $6.6 \pm 1.0 \%)$, glucose levels $(7.7 \pm 2.1 \mathrm{mmol} / \mathrm{l}$ vs $6.9 \pm 1.6 \mathrm{mmol} / \mathrm{l})$ and decreased arterial stiffness (pulse wave velocity $11.2 \pm 2.1 \mathrm{~m} / \mathrm{s}$ vs $10.4 \pm 2.2 \mathrm{~m} / \mathrm{s}$ ). In most patients, the tolerability of trimetazidine was rated as excellent to good, with a low incidence of adverse events.

Keywords: stable coronary artery disease $\bullet$ trimetazidine $\bullet$ Type 2 diabetes mellitus.

\section{Background}

Patients with stable angina not controlled by monotherapy with nitrates, beta blockers, or calcium channel blockers are often treated with combinations of these drugs. There may be adverse effects from, or contraindications to, the use of combinations. In low risk groups, medical treatment appears to be as good an option as percutaneous transluminal coronary angioplasty in terms of averting myocardial infarction, death, or subsequent revascularization. Revascularization procedures are too costly or inaccessible for many patients in developing countries therefore effective and safe medical treatment is needed. Trimetazidine is a less well known anti-anginal drug that controls myocardial ischaemia through intracellular metabolic changes. Trimetazidine has been reported, in some studies, to be better tolerated than combined anti-anginal therapy; however it is not considered in published guidelines. ${ }^{[1,2,3]}$

\section{Patients \& Methods}

Patient selection a total of 101 patients with angina pectoris and T2DM were included in the study at our Rajarajeshwari Medical College \& 
Hospital in Cardiology Department from JAN 2017 to JAN 2018.

\section{Eligibility criteria for inclusion were}

Age >18 years; T2DM; stable angina pectoris, diagnosed by the clinician based on ESC guidelines $^{[4]}$, where the investigator decided to initiate treatment with trimetazidine $35 \mathrm{mg}$ tablets twice daily in addition to optimal medication; the patient was required to read and sign the patient information and consent form in advance.

\section{Study exclusion criteria were}

Contraindications included in the trimetazidine (35 mg) Summary of Product Characteristics; heart failure (New York Heart Association stages III or IV); unstable angina pectoris; Parkinson's disease, extrapyramidal symptoms; severe renal impairment (creatinine clearance $<30 \mathrm{ml} / \mathrm{min}$ ). Study design, end points this was a prospective, observational, noninterventional study.

All patients included in the study were followed up for 6 months (three visits in total: baseline status, month 3 and month 6).

The study end points were: Weekly frequency and severity (Canadian Cardiovascular Society Classification [CCSC]) of angina complaints and the amount of short-acting nitrate products used. Systolic left ventricular function and estimated left atrial filling pressure. Functional status on exercise tolerance test, time to onset of a 1-mm ST-depression, time to onset of angina. Changes in arterial stiffness parameters (pulse wave velocity $[\mathrm{PWV}],{ }^{[5]}$ future science group Effectiveness \& safety of trimetazidine in patients with stable angina pectoris \& T2DM Research Article Changes in HbAlc values. Clinician's global impression of change (CGIC). Documentation of adverse events and other safety parameters.

\section{Study Parameters}

Pulse rate and blood pressure measurements were performed in accordance with professional guidelines after a 5-min rest period on two consecutive occasions, in the sitting position. Functional stage of angina was determined using the CCSC scale from I to $\mathrm{IV}^{[6]}$. The weekly frequency of short-acting nitrate use was recorded. The following laboratory tests were performed, in accordance with applicable protocols, at visit one (patient enrollment) and visit three (month 6): blood glucose, HbA1c, serum urea, serum creatinine, GFR, SGOT, SGPT, CK, total cholesterol, low-density lipoprotein (LDL) cholesterol, high-density lipoprotein (HDL) cholesterol, triglyceride, serum sodium, serum potassium, CRP, uric acid. Echocardiography was used to determine global left ventricular systolic function ejection fraction (EF) and estimated left atrial filling pressure (E/Ea). Results of arterial stiffness (PWV) were recorded with an oscillometric, An exercise tolerance test was used to assess functional status (metabolic equivalents; METs) and time to onset of angina or a 1-mm STdepression. Each patient's clinical status at visits two and three was compared with that observed at the baseline visit; the change in medical condition was assessed by the clinician using the CGIC (on a scale from 0 to 7). Medication used during the observational period After inclusion in the study, patients received trimetazidine $35 \mathrm{mg}$ twice daily in addition to optimal antianginal medication. Patients with moderate renal impairment (creatinine clearance: $30-60 \mathrm{ml} / \mathrm{min}$ ), received trimetazidine $35 \mathrm{mg}$ once daily. After the final visit, patients continued to receive medication in accordance with professional guidelines.

\section{Results}

A total of 101 patients were included in the study. Patient demographic data are shown in Table 1. A total of $60 \%$ of patients (16 patients) had a history of cardiovascular or cerebrovascular events (acute myocardial infarction, percutaneous coronary intervention $[\mathrm{PCI}]$, coronary artery bypass graft, stroke, transient ischemic attack). In addition to stable angina pectoris, patients had the following comorbidities: hyperlipidemia $(88 \%)$, hypertension $(76 \%)$ and peripheral vascular disease $(35 \%)$ Table 1. 
Table 1: Parameters of patients

\begin{tabular}{|c|c|}
\hline Variable & Patients $n=101$ \\
\hline Age (years), mean \pm SD & $68.2 \pm 10.0$ \\
\hline Male/female, $n$ & $49 / 52$ \\
\hline Body weight $(\mathrm{kg})$, mean \pm SD & $90.0 \pm 18.0$ \\
\hline Body height $(\mathrm{cm})$, mean \pm SD & $164.3 \pm 10.8$ \\
\hline BMI $\left(\mathrm{kg} / \mathrm{m}^{2}\right)$, mean $\pm \mathrm{SD}$ & $32.6 \pm 4.0$ \\
\hline Active smoking (\%) & 16 \\
\hline Quit smoking (\%) & 35 \\
\hline Hypertension (\%) & 74 \\
\hline Dyslipidemia (\%) & 90 \\
\hline $\begin{array}{l}\text { Cardiovascular or } \\
\text { cerebrovascular events }(\%)\end{array}$ & 60 \\
\hline Peripheral vascular disease (\%) & 35 \\
\hline ACE inhibitor/ARB (\%) & 85 \\
\hline p-blocker (\%) & 90 \\
\hline Calcium antagonist (\%) & 40 \\
\hline Diuretic (\%) & 26 \\
\hline Statin (\%) & 84 \\
\hline Aspirin, clopidogrel (\%) & 90 \\
\hline
\end{tabular}

Effect of trimetazidine treatment on blood pressure \& pulse rate During 6 months of treatment with trimetazidine but statistically significant reductions in systolic and diastolic blood pressure, and pulse rate were demonstrated compared with baseline values $(\mathrm{p}<0.05$; Table 2). All of these changes demonstrate a feature of observational studies that allows therapy adjustments during the study period, rather than the metabolic effect of trimetazidine treatment. Results indicating changes in hemodynamic parameters were obtained from data of patients who underwent adjustments of anti-ischemic treatment with a mainly hemodynamic effect (long-acting nitrates, $\beta$-blockers, calcium-channel blockers) or any other (antidiabetic, lipid-lowering or blood pressure lowering) therapy adjustments; therefore, data from such patients were excluded from the scientific evaluation. In the analysis performed on the basis of the above criteria, 6 months of trimetazidine treatment was not found to result in any significant change in hemodynamic parameters (systolic and diastolic blood pressure and pulse rate; see Table 2).

Table 2: Systolic and Diastolic blood pressure, and pulse rate, during trimetazidine for 6 months.

\begin{tabular}{|c|c|c|c|c|}
\hline Variable & Baseline visit & Month-3 visit & Month-6 visit & p-value \\
\hline $\begin{array}{c}\text { Systolic blood pressure } \\
(\mathrm{mmHg}) \mathrm{n}=101\end{array}$ & $135.1 \pm 20.2$ & $131.8 \pm 12.1$ & $131.5 \pm 10.2$ & $<0.05$ \\
\hline $\begin{array}{c}\text { Diastolic blood pressure } \\
(\mathrm{mmHg}) \mathrm{n}=101\end{array}$ & $83.4 \pm 10.4$ & $78.4 \pm 8.5$ & $78.1 \pm 7.9$ & $<0.05$ \\
\hline Pulse (1/min) $\mathrm{n}=101$ & $73.6 \pm 11.0$ & $72.6 \pm 8.1$ & $72.1 \pm 7.9$ & $<0.05$ \\
\hline $\begin{array}{c}\text { Systolic blood pressure } \\
(\mathrm{mmHg}) \mathrm{n}=89\end{array}$ & $134.0 \pm 20.8$ & $135.1 \pm 11.8$ & $135.4 \pm 11.0$ & 0.20 \\
\hline $\begin{array}{c}\text { Diastolic blood pressure } \\
(\mathrm{mmHg}) \mathrm{n}=89\end{array}$ & $83.0 \pm 13.0$ & $85.5 \pm 9.6$ & $85.2 \pm 9.8$ & 0.33 \\
\hline Pulse $(1 / \mathrm{min}) \mathrm{n}=89$ & $71.1 \pm 12.2$ & $71.0 \pm 8.9$ & $74.2 \pm 8.0$ & 0.41 \\
\hline
\end{tabular}

\begin{tabular}{|c|c|c|c|c|}
\hline \multicolumn{5}{|c|}{ Table 3: Parameters with trimetazidine for 6 months. } \\
\hline Variable & Baseline visit & Month-3 visit & Month-6 visit & p-value \\
\hline $\begin{array}{c}\text { Number of angina complaints } \\
\text { per week }\end{array}$ & $2.8 \pm 2.4$ & $1.7 \pm 1.7$ & $1.2 \pm 1.4$ & $<0.05$ \\
\hline CCSC & $1.8 \pm 0.6$ & $1.6 \pm 0.5$ & $1.2 \pm 0.7$ & $<0.05$ \\
\hline $\begin{array}{l}\text { Number of nitrate doses used } \\
\text { per week }\end{array}$ & $1.8 \pm 1.0$ & $1.0 \pm 1.2$ & $0.6 \pm 1.1$ & $<0.05$ \\
\hline Echocardiography EF (\%) & $56.0 \pm 10.2$ & - & $56.0 \pm 9.2$ & 0.22 \\
\hline Echocardiography E/Ea & $9.0 \pm 3.4$ & - & $8.8 \pm 3.0$ & 0.57 \\
\hline $\begin{array}{c}\text { Time to onset of ST- } \\
\text { depression (min) }\end{array}$ & $5.4 \pm 2.0$ & - & $6.4 \pm 2.0$ & $<0.05$ \\
\hline $\begin{array}{c}\text { Time to onset of angina } \\
\text { complaints (min) }\end{array}$ & $5.4 \pm 2.2$ & - & $6.4 \pm 2.2$ & $<0.05$ \\
\hline Arterial stiffness PWV (m/s) & $11.0 \pm 2.0$ & - & $11.0 \pm 2.2$ & $<0.05$ \\
\hline
\end{tabular}

CCSC: Canadian Cardiovascular Society Classification; E/Ea: Estimated left atrial filling pressure; EF: Ejection fraction; PWV: Pulse wave velocity. 
Effect of trimetazidine treatment of angina complaints \& short-acting nitrate consumption

During trimetazidine treatment, the weekly frequency of angina symptoms showed significant reductions at visit two (month 3) compared with baseline, and there was a tendency toward further reductions during 6 months of treatment ( $p<$ $0.05)$. The severity of angina complaints, mean CCSC score, and short-acting nitrate consumption, all showed a clinically meaningful, significant improvement during the 6-month course of treatment with trimetazidine $(\mathrm{p}<0.05$; Table 3).

$\begin{array}{lllr}\text { Effect of } & \text { trimetazidine } & \text { treatment on } \\ \text { parameters of exercise } & \text { tolerance } & \text { test, }\end{array}$

echocardiography \& arterial stiffness Functional status METs and the time to onset of angina or a 1-mm ST-depression were assessed using an exercise tolerance test. The 6-month course of treatment with trimetazidine resulted in a clinically effective, significant improvement in all three parameters $(\mathrm{p}<0.05$; Table 3$)$. No significant change was observed in global left ventricular systolic function $\mathrm{EF}$ and estimated left atrial filling pressure $(\mathrm{E} / \mathrm{Ea})$ during the 6-month period of therapy $(\mathrm{p}=0.22$ and $\mathrm{p}=0.57$, respectively; Table 3). Parameters of arterial stiffness were also determined in a subgroup of 16 patients; PWV showed significant improvement.(p $<0.05$, respectively; Table 3 )

\begin{tabular}{|c|c|c|c|}
\hline Laboratory parameters & Baseline visit & Month-6 visit & p-value \\
\hline Blood glucose $(\mathrm{mmol} / \mathrm{A})$ & $7.4 \pm 3.1$ & $6.4 \pm 1.52$ & $<0.05$ \\
\hline HbA1c (\%) & $7.0 \pm 1.2$ & $6.42 \pm 0.88$ & $<0.05$ \\
\hline Total cholesterol $(\mathrm{mmol} / \mathrm{l})$ & $4.9 \pm 1.2$ & $4.7 \pm 1.03$ & $<0.05$ \\
\hline LDL cholesterol (mmol/1) & $2.0 \pm 0.9$ & $2.5 \pm 0.7$ & $<0.05$ \\
\hline HDL cholesterol $(\mathrm{mmol} / \mathrm{l})$ & $1.2 \pm 0.4$ & $1.2 \pm 0.4$ & 0.76 \\
\hline Triglyceride (mmol/1) & $2.11 \pm 0.98$ & $2.14 \pm 0.12$ & $<0.05$ \\
\hline SGOT $(\mathrm{U} /)$ & $30.14 \pm 14.24$ & $30.85 \pm 10.01$ & 0.56 \\
\hline SGPT (U/) & $29.54 \pm 13.60$ & $29.85 \pm 12.13$ & 0.11 \\
\hline Urea $(\mathrm{mmol} / \mathrm{\Lambda})$ & $7.50 \pm 2.35$ & $7.01 \pm 1.19$ & 0.29 \\
\hline Creatinine $(\mathrm{mmol} / \mathrm{A})$ & $93.0 \pm 29.01$ & $91.12 \pm 22.01$ & $<0.05$ \\
\hline Sodium $(\mathrm{mmol} / \mathrm{h})$ & $139.06 \pm 4.01$ & $140.46 \pm 3.25$ & 0.55 \\
\hline Potassium $(\mathrm{mmol} / \mathrm{A})$ & $4.65 \pm 0.85$ & $4.66 \pm 0.75$ & 0.66 \\
\hline CRP $(\mathrm{mg} / \mathrm{l})$ & $7.42 \pm 5.58$ & $5.10 \pm 5.01$ & $<0.05$ \\
\hline Uric acid $(\mu \mathrm{mol} / 1)$ & $343.79 \pm 80.02$ & $324.82 \pm 69.77$ & $<0.05$ \\
\hline
\end{tabular}

\section{Changes in laboratory parameters during 6 months of treatment with trimetazidine}

A significant and clinically meaningful $31 \%$ reduction in CRP, $11 \%$ in blood glucose, $7 \%$ in HbA1c levels, and a clinically minimal but statistically significant decrease in total cholesterol, LDL cholesterol, triglyceride, uric acid, and creatinine $(\mathrm{p}<0.05)$ were shown; no significant change was observed in HDL cholesterol, SGPT, SGOT, urea nitrogen, potassium, and sodium levels (Table 4).

\section{Adverse Events}

Out of 101 patients included in the study, $1.1 \%$ (8 patients) experienced treatment-related adverse events during 6 months of therapy. We recorded 6 cases of hospitalization: two cases of acute myocardial infarction treated with PCI, 3 cases of elective coronary angiography and PCI, and one case of atrial fibrillation. No deaths were reported in the study period. Trimetazidine therapy was discontinued in a total of three cases (hand tremor in one case and gait disturbance in one case)

\section{Discussion}

According to our results, trimetazidine based therapy proved to be effective in the vast majority of patients. The weekly frequency and severity of angina symptoms and the amount of short-acting nitrate consumption showed significant regression in terms of clinical symptoms; additionally, patients experienced improvements in QoL. 
On echocardiography, no significant changes occurred in either systolic left ventricular function or estimated left atrial filling pressure during the 6-month course of treatment. In contrast to our results, previous clinical studies and metaanalyses demonstrated substantial improvement in $\mathrm{EF}^{[4,5]}$. According to our echocardiography results, no progression suggestive of diabetic cardiomyopathy was detected during 6 months of treatment with trimetazidine.

In patients with T2DM, insulin resistance also affects the myocardium. Reduced glucose uptake caused by insulin resistance results in a shift in energy production processes toward $\beta$-oxidation of free fatty acids, which is energetically less effective than glycolysis and results in absolute and relative ATP deficiency during ischemia. By selectively blocking the 3-ketoacyl-CoA thiolase enzyme, trimetazidine switches the energy substrate preference from fatty acid oxidation to glucose oxidation ${ }^{[6]}$. All these pathophysiological mechanisms lead to the improved glycemic status documented during trimetazidine therapy ${ }^{[7,8]}$. Based on available published literature, our study is the first large-scale clinical trial to investigate the long-term effects of trimetazidine on blood glucose and $\mathrm{HbA1c}$ levels in patients with SCAD and T2DM.

In our study, significant positive changes were demonstrated in terms of blood glucose and HbA1c levels in patients with T2DM; moreover, this tendency to improvement was sustained during the 6-month course of trimetazidine treatment. In the long term, improving glycemic status may also have a beneficial effect on the occurrence of cardiovascular events.

Arterial stiffness parameters, as predictors of vascular target organ damage, were also determined in a subgroup of patients $(n=16)$ in our study. In addition to increasing the effectiveness of energy production, the metabolic modulator properties of trimetazidine also stabilize intracellular phosphocreatine stores, decrease cellular acidosis and intracellular free calcium levels and protect against damage caused by free radicals. Based on fundamental research, all these pathophysiological mechanisms lead to an improvement in endothelial function ${ }^{\text {[9-14] }}$

A clinical study in patients with heart failure demonstrated a beneficial effect of trimetazidine on the progression of endothelial dysfunction, as measured by flow-mediated vasodilation ${ }^{[15]}$. Another study found that the regression of angina symptoms in patients with peripheral arterial disease was not accompanied by a positive change in endothelial dysfunction ${ }^{[16]}$.

Our study is the first clinical trial to investigate the long-term effects of trimetazidine on parameters of arterial stiffness, in other words, PWV. PWV showed significant improvement during 6 months of trimetazidine treatment. ${ }^{[17-19]}$.

During the 6-month course of treatment with trimetazidine in our study, a significant decrease in CRP levels was observed, showing good correlation with findings from previous studies ${ }^{[20]}$. According to the meta-analysis of Zhou \& Chen, the extent of decrease in CRP levels was dependent on variations in patient characteristics: a higher baseline CRP level was associated with a more pronounced CRP reduction ${ }^{[20]}$. This finding is also supported by the result of our subgroup analysis: patients with coexisting T2DM and peripheral arterial vascular disease had the most benefit from reduced CRP levels, which occurred at a significantly elevated baseline level. It should be noted that, in our study, of the laboratory parameters known to be independent risk factors, uric acid, triglyceride and total cholesterol levels showed a clinically moderate but statistically significant decrease during trimetazidine treatment. However, this effect is presumably not exclusively attributable to the metabolic modulator features of trimetazidine. During treatment, patients with stable angina pectoris undergo life changes involving an increase in physical activity owing to pain relief and an improved QoL. All these factors lead to a moderate $(3.5 \%)$ reduction in body weight and secondary improvement in metabolic status, which was also demonstrated in our study. 
In summary, according to ESC guidelines and recently published expert documents, the medical treatment of stable angina has to be individualized taking into account comorbidities and risk factors ${ }^{[21,22]}$. In patients with SCAD and T2DM, the optimal antianginal agent should not only relieve anginal symptoms but also improve the glucose profile. Also, the choice of antianginal agents must suit the patient's hemodynamic status (optimal heart rate and blood pressure). In patients with systolic BP levels less than $120 \mathrm{mmHg}$, drugs with limited impact on BP are preferred. Also, in patients with a $\mathrm{HR}<60 \mathrm{bpm}$, drugs with no impact on HR are optimal. In these cohorts of patients, the nonhemodynamic antianginal agents, ranolazine at first- and second-line, and trimetazidine at third-line therapy, are recommended. Currently, trimetazidine may be viewed as a detrimental choice due to limited data for favorable metabolic effects in T2DM patients. However, based on the results of our clinical study and data reported in the published literature discussed above, we conclude that, in diabetic individuals, 6 months of trimetazidine-based therapy improved glucose metabolism, significantly lowered HbA1c and glucose levels, and it could be used effectively and safely in patients with SCAD and T2DM.

\section{Summary Points}

- Cardiovascular diseases are the leading cause of mortality worldwide and the main cause of death in individuals with diabetes.

- Anti-ischemic antianginal agents such as trimetazidine may be useful in patients with stable coronary artery disease (SCAD) and Type 2 diabetes mellitus (T2DM).

- In this 6-month, prospective, observational, noninterventional, openlabel clinical study, we assessed the effectiveness and safety of trimetazidine in 101 patients with stable angina pectoris and T2DM.
- Trimetazidine-based therapy for 6 months was effective in SCAD, with significant improvements from baseline $(\mathrm{p}<0.05)$ in: number of angina attacks/week $(2.9 \pm 2.4$ vs $1.1 \pm 1.6)$, angina severity ( $2.8 \pm 0.8$ vs $1.5 \pm 0.8$ [CCSC] $)$..

- Trimetazidine-based therapy significantly $(p<0.05)$ improved baseline glucose metabolism, lowered HbA1c $(7.1 \pm 1.0 \%$ vs $6.6 \pm 1.0 \%)$, glucose levels $(7.7 \pm 2.1$ $\mathrm{mmol} / \mathrm{l}$ vs $6.9 \pm 1.6 \mathrm{mmol} / \mathrm{l})$ and decreased arterial stiffness (PWV $11.2 \pm 2.1 \mathrm{~m} / \mathrm{s}$ vs $10.4 \pm 2.2 \mathrm{~m} / \mathrm{s}$ ).

The tolerability of trimetazidine was rated as excellent or good in the majority of patients, and the incidence of adverse events was low.

\section{References}

1. Aksoyek 1996 \{published data only\} Aksoyek S, Kabukcu M, Ovunc K, Kabakci G, Aytemir K, Oto A. Clinical efficacy of trimetazidine instable angina pectoris: A doubleblind placebo controlled study [Kararli angina pektoriste trimetazidine'in klinik etkinligi: cift kor, plasebo kontrollu calisma]. Turk Kardiyoloji Dernegi Arsivi 1996;24 (5):261-2+289-92.

2. Bermudez-HT 1995 \{published data only\} Bermúdez Arias F, Baptista Arrieta G, Fernández A, Madrid L, Colmenares R, García F, et al. First american study of trimetazidine (FAST) [Primer estudio americano de trimetazidine (FAST)]. Archivos Venezolanos de Farmacología y Terapéutica 1995;14(1):39- 53.

3. Bermudez-NT 1995 \{published data only\} Bermúdez Arias F, Baptista Arrieta G, Fernández A, Madrid L, Colmenares R, García F, et al. First american study of trimetazidine (FAST) [Primer estudio americano de trimetazidine (FAST)]. Archivos Venezolanos de Farmacología y Terapéutica 1995;14(1):39- 53. 
4. Stamler J, Vaccaro O, Neaton JD, Wentworth D. Diabetes, other risk factors, and 12-yr cardiovascular mortality for men screened in the multiple risk factor intervention trial. Diabetes Care 16(2), 434-444 (1993).

5. Padial LR. Clinical benefits of trimetazidine in patients with coronary artery disease and diabetes mellitus. Heart Metab. 45, 26-29 (2009).

6. Canadian Cardiovascular Society. Angina classification scale. www.ccs.ca/en/.

7. Gao D, Ning N, Niu X, Hao G, Meng Z. Trimetazidine: a meta-analysis of randomized controlled trials in heart failure. Heart 97(4), 278-286 (2011).

8. Fragasso G, Rosano G, Baek SH et al. Effect of partial fatty acid oxidation inhibition with trimetazidine on mortality and morbidity in heart failure: results from an international multicentre retrospective cohort study. Int. J. Cardiol. 163(3), 320325 (2013).

9. Kantor PF, Lucien A, Kozak R, Lopaschuk GD. The antianginal drug trimetazidine shifts cardiac energy metabolism from fatty acid oxidation to glucose oxidation by inhibiting mitochondrial long-chain 3ketoacyl coenzyme A thiolase. Circ. Res. 86(5), 580-588 (2000) .

10. Fragasso G, Piatti PM, Monti L et al. Short- and long-term beneficial effects of trimetazidine in patients with diabetes and ischemic cardiomyopathy. Am. Heart J. 146(5), e18 (2003).

11. Monti LD, Setola E, Fragasso G et al. Metabolic and endothelial effects of trimetazidine on forearm skeletal muscle in patients with Type 2 diabetes and ischemic cardiomyopathy. Am. J. Physiol. Endocrinol. Metab. 290(1), E54-E59 (2006)

12. Guarnieri C, Muscari C. Beneficial effects of trimetazidine on mitochondrial function and superoxide production in the cardiac muscle. Cardiovasc. Drugs Ther. 4(Suppl. 4), 814-815 (1990).

13. Coetzee WA, Enous R, Opie LH. Trimetazidine: effects on delayed after depolarizations (DADs) and upstroke velocity of the action potential. Cardiovasc. Drugs Ther. 4(Suppl. 4), 806807 (1990).

14. Guarnieri C, Muscari C. Effect of trimetazidine on mitochondrial function and oxidative damage during reperfusion of ischemic hypertrophied rat myocardium. Pharmacology 46(6), 324331 (1993).

15. Tritto I, Wang P, Kuppusamy P, Giraldez R, Zweier JL, Ambrosio G. The antianginal drug trimetazidine reduces neutrophil-mediated cardiac reperfusion injury. J. Cardiovasc. Pharmacol. 46(1), 89-98 (2005).

16. Lavanchy N, Martin J, Rossi A. Antiischemic effects of trimetazidine: 31PNMR spectroscopy in the isolated rat heart. Arch. Int. Pharmacodyn. Ther. 286(1), 97-110 (1987).

17. Lagadic-Gossmann D, Le Prigent K, Feuvray D. Effects of trimetazidine on $\mathrm{pH}$ regulation in the rat isolated ventricular myocyte. Br. J. Pharmacol. 117(5), 831838 (1996).

18. Belardinelli R, Solenghi M, Volpe L, Purcaro A. Trimetazidine improves endothelial dysfunction in chronic heart failure: an antioxidant effect. Eur. Heart J. 28(9), 1102-1108 (2007).

19. Vitale C, Marazzi G, Pelliccia F et al. Trimetazidine improves exercise performance in patients with peripheral arterial disease. Pharmacol. Res. 63(4), 278-283 (2011).

20. Lenkey Z, Illyes M, B ' ocskei R “ et al. Comparison of arterial stiffness parameters in patients with coronary artery disease and diabetes mellitus using Arteriograph. Physiol. Res. 63(4), 429-437 (2014). 
21. Lacy PS, O’Brien DG, Stanley AG, Dewar MM, Swales PP, Williams B. Increased pulse wave velocity is not associated with elevated augmentation index in patients with diabetes. J. Hypertens. 22(10), 19371944 (2004).

22. Westerbacka J, Uosukainen A, Makimattila S, Schlenzka A, Yki-J arvinen $\mathrm{H}$. Insulin-induced decrease in large artery stiffness is impaired ". in uncomplicated type 1 diabetes mellitus. Hypertension 35(5), 1043-1048 (2000).

23. Zhou X, Chen J. Is treatment with trimetazidine beneficial in patients with chronic heart failure? PLoS ONE 9(5), e94660 (2014).

24. Ambrosio G, Komajda M, Mugelli A, Lopez-Sendon J, Tamargo J, Camm J. Management of stable angina: a commentary on the 'European Society of Cardiology guidelines. Eur. J. Prev. Cardiol. 23(13), 1401-1412 (2016).

25. Manolis AJ, Poulimenos LE, Ambrosio G et al. Medical treatment of stable angina: a tailored therapeutic approach. Int. J. Cardiol. 220, 445-453 (2016). 